Journal of Advanced Research in Fluid Mechanics and Thermal Sciences

Journal homepage: www.akademiabaru.com/arfmts.html ISSN: 2289-7879

\title{
Characterization of Crude Palm Oil (CPO), Corn Oil and Waste Cooking Oil for Biodiesel Production
}

\author{
Siti Nurul Akmal Yusof ${ }^{1,}$, Siti Mariam Basharie ${ }^{2}$, Nor Azwadi Che Sidik ${ }^{1}$, Yutaka Asako ${ }^{1}$, Saiful Bahri \\ Mohamed $^{3}$
}

1 Department of Mechanical Precision Engineering, Malaysia-Japan International Institute of Technology, Universiti Technologi Malaysia, Jalan
Sultan Yahya Petra, 54100 Kuala Lumpur, Malaysia
2 Centre for Diploma Studies, Universiti Tun Hussein Onn Malaysia, EDU Hab Pagoh, 84600 Johor, Malaysia
3 School of Manufacturing Technology, Faculty of Innovative Design and Technology, Universiti Sultan Zainal Abidin, 21300 Terengganu, Malaysia

\section{ARTICLE INFO}

Article history:

Received 29 June 2021

Received in revised form 23 July 2021

Accepted 27 July 2021

Available online 28 August 2021

\section{Keywords:}

Biodiesel; transesterification process; esterification process; free fatty acids

\section{ABSTRACT}

Biodiesel production is the reaction of raw oils with mixing and heating within catalyst and methanol. The raw oils usually come from vegetable oils and animal fats. Vegetable oils are a promising feedstock for biodiesel production since they are renewable in nature. Nevertheless, the physical properties of biodiesel pose some acute problems when used in an unmodified engine. It is important to diesel and biodiesels because it impacts components such as the fuel pump. Therefore, this paper intends to investigate the properties of biodiesel samples in terms of viscosity, density, flash point and acid values at different bio lipids and different mixing time. The evaluation is carried out on the three types of biodiesels: CPO, corn oil, and waste cooking oil. Methanol was chosen over the others for the transesterification process because it was cheaper. The esterification process, which reduces the amount of free fatty acids in the crude oil, will be performed with the help of an acid catalyst. Alkaline catalysts, in contrast, are used for the transesterification process. The comparison of all the samples shows that CPO is the better biodiesel than the other due to the physical properties of kinematic viscosity, density and flashpoint.

\section{Introduction}

Because of the dwindling world petroleum supply and the environmental issues that are happening now, there is a great demand for alternative fuels to replace or lessen petroleum-based fuel dependency and to control greenhouse gas (GHG) emissions into the environment. Other than reducing fossil fuel consumption [1-2], a novel automotive engine with post-combustion emission control devices should be developed to reduce GHG emissions and improve the efficiency of energy systems [3-5]. Biodiesel has recently been considered as the best candidate for it. It can be used in any ignition compression engine without the need for modification [6-9].

\footnotetext{
* Corresponding author.

E-mail address: sitinurulakmalyusof@gmail.com
}

https://doi.org/10.37934/arfmts.86.2.136146 
Chemically, biodiesel is a mixture of methyl esters with long-chain fatty acids. It is usually made from non-toxic, biological resources such as vegetable oil, animal fat, or cooking oil [6,10-11]. Biodiesel is one of the current favorites to be the next-generation fuel. It is made from renewable biological sources such as vegetable oils and animal fats. It is biodegradable, non-toxic, and has a low emission profile. Chemically, biodiesel is fatty acid methyl esters (FAME). FAME will be produced by transesterification of oils and fats with methanol in the presence of suitable catalysts.

The most common way to produce biodiesel is by trans-esterifying oils and animal fats with methanol (preferred over the others due to its low cost). Compared with other alcohol such as ethanol, propanol, and butanol, methanol has a lower molecular mass [12-13]. When the raw oil has a high percentage of FFA and water, it must be retreated by using esterification process before it can be catalyzed. It is because the process depends on the FFA contents in raw oil. If the FFA contents are more than $2 \%$, the transesterification process is not feasible. The FFA must be less than $2 \%$ to ensure transesterification reaction possible [14-18].

Biodiesel can be produces from straight vegetable oil, animal oil/fats, and waste cooking oil. Soya bean is commonly used for biodiesel production in the United States, whereas; rapeseed oil is used in many European countries. Corn oil also is one of the sources of biodiesel production. Although biodiesel is commonly made from soybean or rapeseed oil, as corn oil refining technology improves, it is expected to become a larger source for biodiesel and a backup source for large-scale soybean crop failures. Other industrial sectors are already using corn oil, including paint, salve, rustproofing for metal surfaces, inks, textiles, nitroglycerin, and insecticides. It is also sometimes used as a carrier for molecules inside pharmaceutical drug preparations. The corn can be grown and can be harvested in months, and can be planted again, and it is suitable to produce in Malaysia because of warm and rainy season during the year. However, Asian has a competition with the edible oils market, so they explore non-edible seed oil, such as jatropha and pongamia as biodiesel raw oils [19]. But the gestation period of a couple of years are needed before these plants start producing seeds and oil.

On the other hand, Malaysia is using coconut oil and palm oil for biodiesel production. But because palm oil contains a substantial amount of saturated fat, biodiesel from palm oil has a poor low-temperature tolerance $[17,20]$. To exploit South Asian closeness with South-East Asian countries, jatropha and palm biodiesel were inspected to study the physicochemical features to get the optimal mix to achieve better low-temperature tolerance with better oxidation stability. Another feedstock to produce biodiesel is used or waste cooking oil, which is much less expensive than edible vegetable oil. It will be one of the promising alternatives to edible vegetable oils. In Malaysia, for example, most palm oil is converted into cooking oil, making palm oil biodiesel difficult to come by. In many regions, waste cooking oil and fats cause considerable disposal issues; this problem can be avoided by turning these waste cooking oil into something useful. Waste cooking oil can be used as an alternative fuel, biodiesel, and diesel engine. Waste cooking oil has a lot of commercial potentials since it can be used to make biodiesel [21], polyurethane (polyol), and bitumen [22], all of these can minimize reliance on natural resources.

Regarding standard (ASTM D 6751-07 or EN 14214 and EN14105), biodiesel should satisfy several specifications, which must be $99.7 \%$ ester [23]. Because of the physical qualities that happened in biodiesel, handling and use must be extra careful. In terms of lubricity, the significant increase in even concentrations at $3 \%$ or less of the biodiesels indicates that biodiesel additives can improve diesel operation and lengthen component life. However, obtaining esters in biodiesel is not an easy task as the current technology in manufacturing and refining biodiesel is still not so economically favorable [24]. Thus, the purpose of this study is to investigate the properties of three biodiesel samples in terms of viscosity, density, flash point, and acid values at different bio-lipids and different mixing times. 


\section{Methodology}

\subsection{Material}

Three types of raw oils will be investigated in this research: CPO, corn oil, and waste cooking oil. The esterification process, which reduces the quantity of free fatty acid in raw oils, will be carried out with the help of an acid catalyst. Simultaneously, an alkaline catalyst is employed in the transesterification process. Methanol is chosen over the others for the transesterification process since it is less expensive. Three samples from CPO, corn oil, and waste cooking oil were used as feedstock. Each sample contains approximately 100 milligrams of raw oils in each beaker.

\subsection{The Process of Determining the Free Fatty Acid (FFA) Content}

The titration process is the process to investigate the amount of water and FFA in raw oils. If the FFA level is too high, it may cause problems such as soap formation. The chemical solution used for the titration process is $99 \%$ pure Isopropyl alcohol, distilled water, and phenolphthalein solution. The purpose of conducting the titration process is to lessen the FFA content in raw oils.

The free fatty acid value is calculated by the formula

$\mathrm{AV}=\frac{(\text { sample }- \text { ethanol } 95 \%) \times N K O H \times 56.1}{m}$

where $\mathrm{N}$ its exact normality of $\mathrm{KOH}$, and $m$ is the mass in $\mathrm{g}$ of the sample. And the percentage of FFA is given by

$$
\begin{aligned}
\% \mathrm{FFA} & =\frac{m l \mathrm{KOH} \times m l \mathrm{AV}}{\text { sample weight } \times 10} \\
& =\frac{A v}{\text { Factor conversion }}
\end{aligned}
$$

Factor conversion is taken from AOCS official method Ca 5a-40, and a detailed explanation is documented in [25].

A typical titration began with a beaker or Erlenmeyer flask containing a precise volume of the reactant and a small amount of indicator and placed underneath a burette containing the reagent. The set-up is as shown in Figure 1.

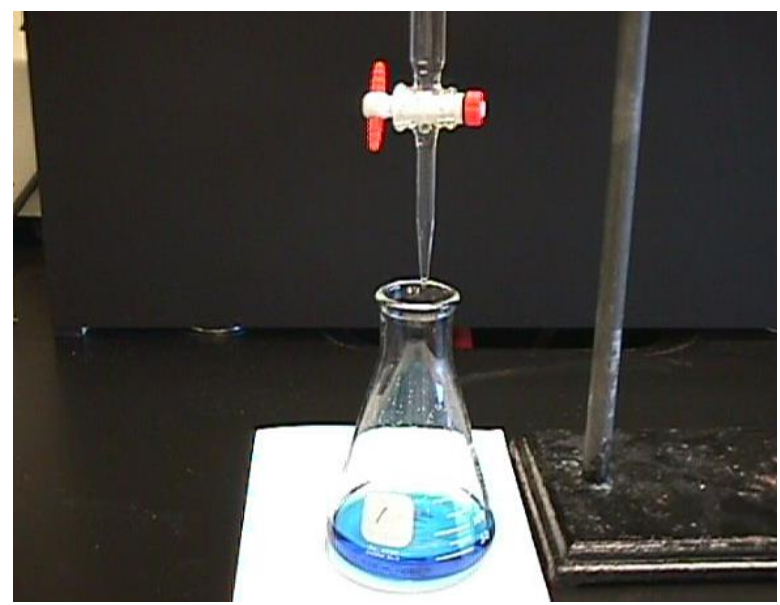

Fig. 1. The set-up of titration process 
In a typical titration, the titrant in the burette is added to the solution in the Erlenmeyer flask until the indicator changes colour to show that the reaction is complete. By controlling the amount of reagent added to the reactant, it is possible to detect the indicator's point. As long as the indicator has been chosen correctly, this should also be the point where the reactant and reagent neutralize each other, and, by reading the scale on the burette, the volume of the reagent can be measured.

\subsection{Esterification Process}

Esterification is the reaction process that produces carboxylic acid and alcohol to lessen the FFA in the contents of raw oils. This reaction can be catalysed by the presence of $\mathrm{H}+$ ions and mixing with methanol. Sulphuric acid $\mathrm{H}_{2} \mathrm{SO}_{4}$ will be used as a catalyst for this reaction. At the end of the esterification reaction, the acid catalyst must be neutralized to isolate the product.

\subsection{Transesterification Process}

After reducing the FFA acid below $1 \%$, the transesterification process takes place to produce biodiesel. The process must be conducted in two different mixing times, which are 30 minutes, 60 minutes, and 120 minutes. The temperature of heating is $600 \mathrm{C}$ to $700 \mathrm{C}$. These processes are quite similar to the esterification process, where it is needed to mix with methanol and catalyst. For this process, the alkaline catalyst is preferred. The alkaline catalyst used is potassium hydroxide (KOH), and Figure 2 shows the transesterification process.

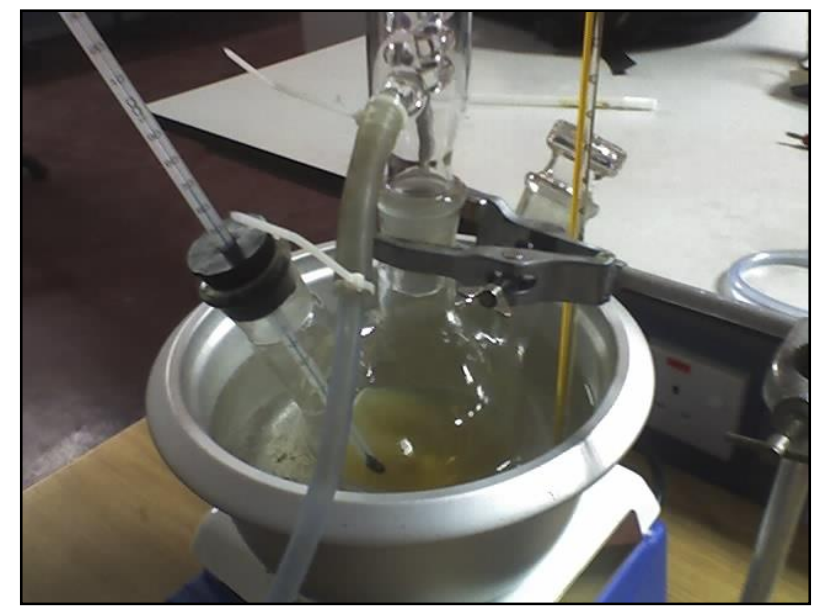

Fig. 2. Transesterification process

\subsection{Washing Process}

In this stage, the FAME has separated from the glycerol, excess methanol, and catalyst. Pure FAME can be obtained by removing the glycerol from the biodiesel samples as shown in Figure 3 . FAME, however, is certainly not pure fuel. Water washing is a great way to get rid of both contaminants. It can also eliminate any residuals in FAME, such as sodium salt and soaps. 


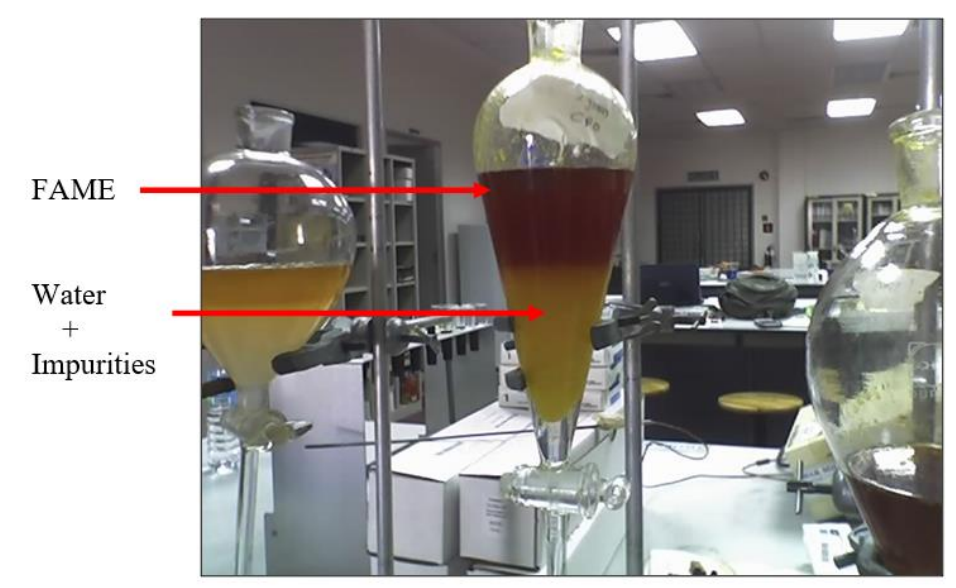

Fig. 3. Washing process to remove the impurities in FAME

\section{Results}

\subsection{Physical Properties}

The results of 9 samples of biodiesel which be trans esterified at different mixing times, can be seen in Table 1. The color of biodiesel samples from corn oil does not differ much from the samples of waste cooking oil. But, the color of samples biodiesel of CPO is like dark orange color, which is different from the other sample.

\section{Table 1}

Transesterification process of 9 samples at different mixing times

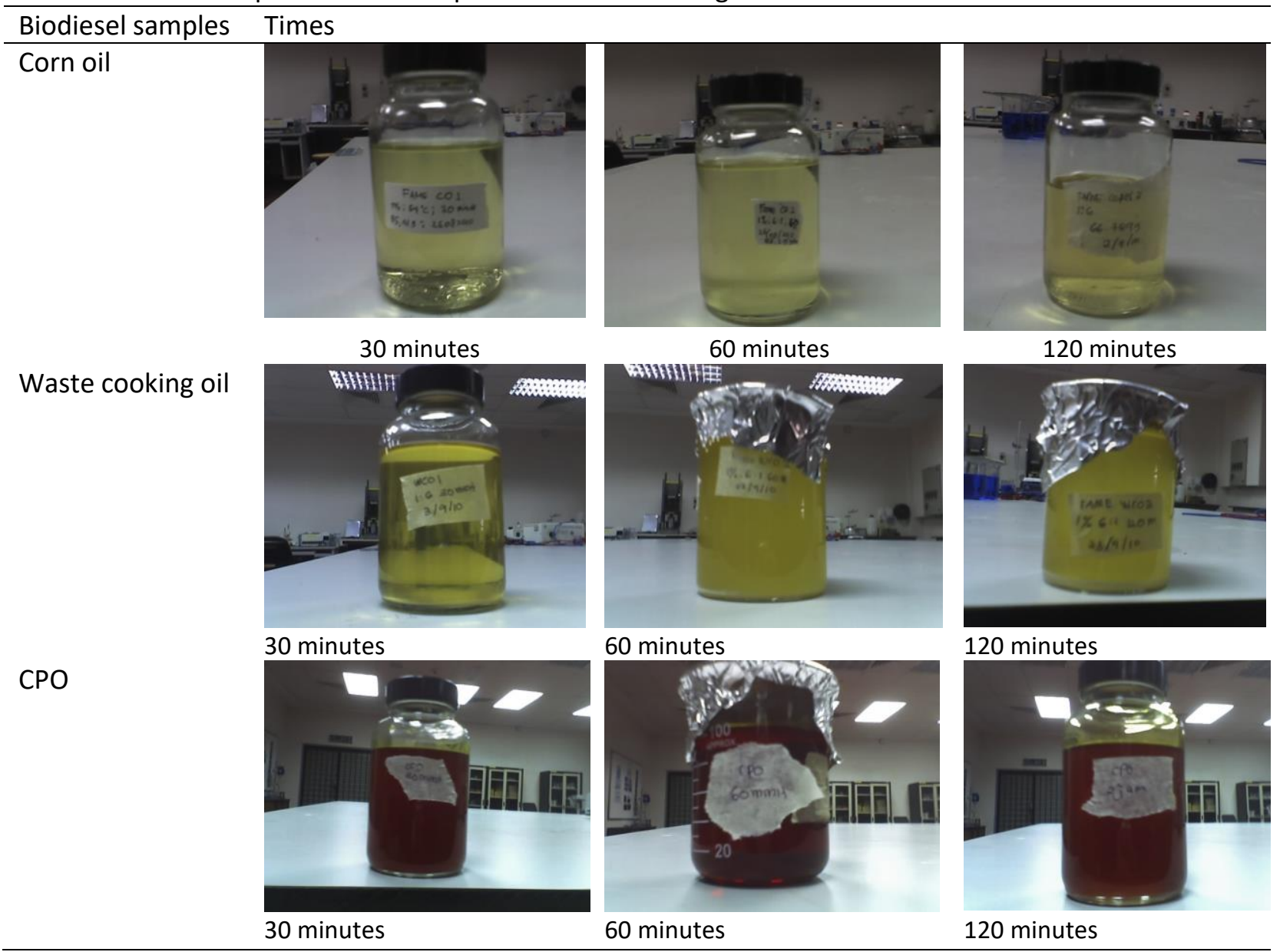


Table 2 shows the result of the physical properties of biodiesel samples.

\section{Table 2}

Result for physical properties of biodiesel samples

\begin{tabular}{|c|c|c|c|c|c|}
\hline Feedstock & Time (min) & $\begin{array}{l}\text { Kinematic } \\
\text { Viscosity at } 40^{\circ} \mathrm{C}\left(\mathrm{mm}^{2} / \mathrm{s}\right)\end{array}$ & $\begin{array}{l}\text { Density } \\
\left(\mathrm{g} / \mathrm{cm}^{3}\right)\end{array}$ & $\begin{array}{l}\text { Acid value } \\
\text { (mg KOH/g) }\end{array}$ & $\begin{array}{l}\text { Flash point } \\
\left({ }^{\circ} \mathrm{C}\right)\end{array}$ \\
\hline Corn oil & - & 26.7 & 0.9088 & 0.5565 & \\
\hline Corn oil & 30 & 3.5 & 0.8588 & 0.555 & 169 \\
\hline Corn oil & 60 & 3.4 & 0.8568 & 0.533 & 171 \\
\hline Corn oil & 120 & 3.3 & 0.8566 & 0.528 & 174 \\
\hline Waste cooking oil & - & 32.2 & 0.9024 & 0.5599 & \\
\hline Waste cooking oil & 30 & 3.5 & 0.865 & 0.550 & 168 \\
\hline Waste cooking oil & 60 & 3.5 & 0.8649 & 0.544 & 172 \\
\hline Waste cooking oil & 120 & 3.5 & 0.8648 & 0.537 & 176 \\
\hline CPO & - & 32.8 & 0.8953 & 6.786 & \\
\hline $\mathrm{CPO}$ & 30 & 3.5 & 0.8647 & 2.088 & 172 \\
\hline CPO & 60 & 3.4 & 0.8598 & 1.634 & 175 \\
\hline $\mathrm{CPO}$ & 120 & 3.3 & 0.8549 & 1.543 & 176 \\
\hline
\end{tabular}

\subsection{The Comparison of The Kinematic Viscosity of Corn Oil, Waste Cooking Oil and CPO}

Kinematic viscosity of the corn oil, waste cooking oil, and CPO is $26.7 \mathrm{~mm}^{2} / \mathrm{s}, 32.2 \mathrm{~mm}^{2} / \mathrm{s}$ and $32.8 \mathrm{~mm}^{2} / \mathrm{s}$, respectively. These are the results from the raw materials. As can be seen in Figure 4, differences of kinematic viscosity values between of the 9 biodiesel samples are too small after transesterification process. However, there are big difference of kinematic viscosity values between raw materials and biodiesel samples. These 9 samples are within the range standards $1.9 \mathrm{~mm}^{2} / \mathrm{s}$ to $6.0 \mathrm{~mm}^{2} / \mathrm{s}$ that were determined from ASTM D-6751. As the time taken for the transesterification is increased, kinematics viscosity will be decreased. This can be seen in Figure 4 .

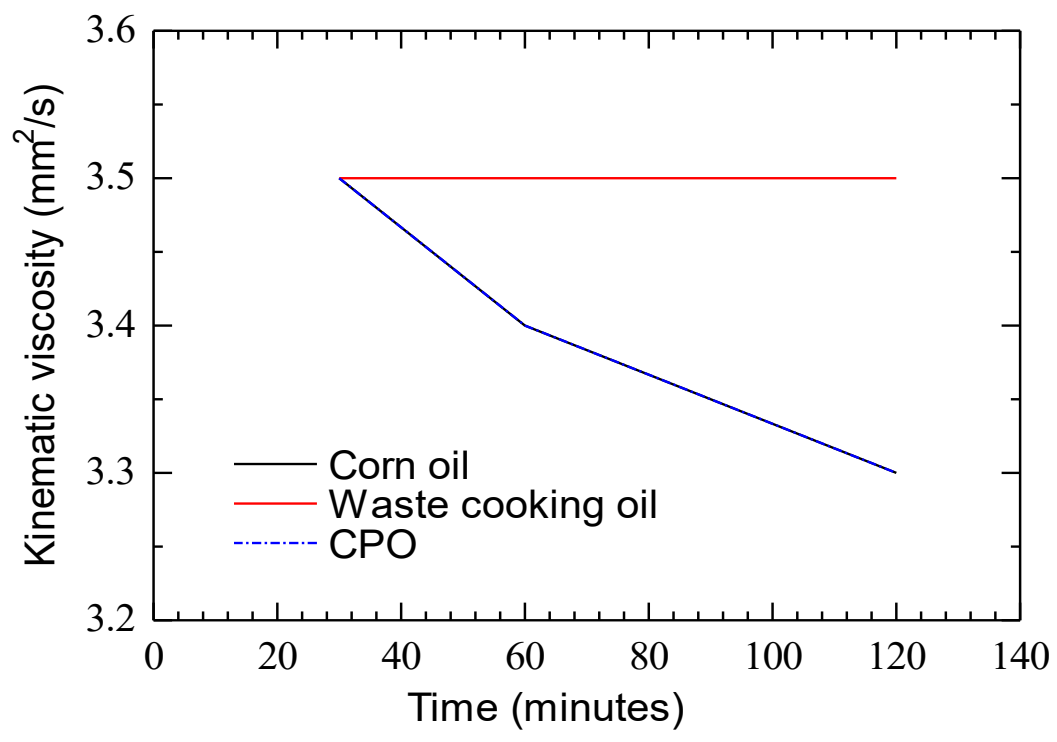

Fig. 4. The comparison of the kinematic viscosity of corn oil, waste cooking oil and CPO 
This result has a good agreement with the previous studies $[10,26]$. The viscosity of the biodiesel derived from waste cooking oil decreased 10 times compared to the original waste cooking oil samples. Results obtained in this study [27] indicated that the kinematic viscosity absolutely no change in time for the sample of waste cooking oil. But this still apply because it still falls between the ranges of standard. There are many factors that could lead to different results even though using the same sample. For an example, Malaysia is known as food heaven. Many restaurants provide food, and of course, they used a lot of cooking oil. In this case, necessarily the kinematic viscosity of waste cooking oil is different.

The properties of final product strongly depend on the yield of methyl ester (purity of methyl ester phase). The presence of glyceride types, in particular, in the fuel can cause serious problems in commercial applications. According to EN 14214 biodiesel standard, there are strict limitations for both free and total glyceride contents of biodiesel and the level of methyl ester content. Although the amounts of free glyceride and total glyceride were not measured, the purity of biodiesel can be determined by using the viscosity measurement.

\subsection{The Comparison of The Density of Corn Oil, Waste Cooking Oil and CPO}

At the start of the research, the density of the raw material has to be determined in order to know the differences between the raw material with biodiesel samples. The density of corn oil is $0.9088 \mathrm{~g} / \mathrm{cm}^{3}$, waste cooking oil is $0.9024 \mathrm{~g} / \mathrm{cm}^{3}$, and CPO is $0.8953 \mathrm{~g} / \mathrm{cm}^{3}$.

The density for all the samples does not differ much in this study. Results for all samples can be seen in Figure 5. Note that a small value of axis in the y-direction was used in the figure since the difference for all the results was small.

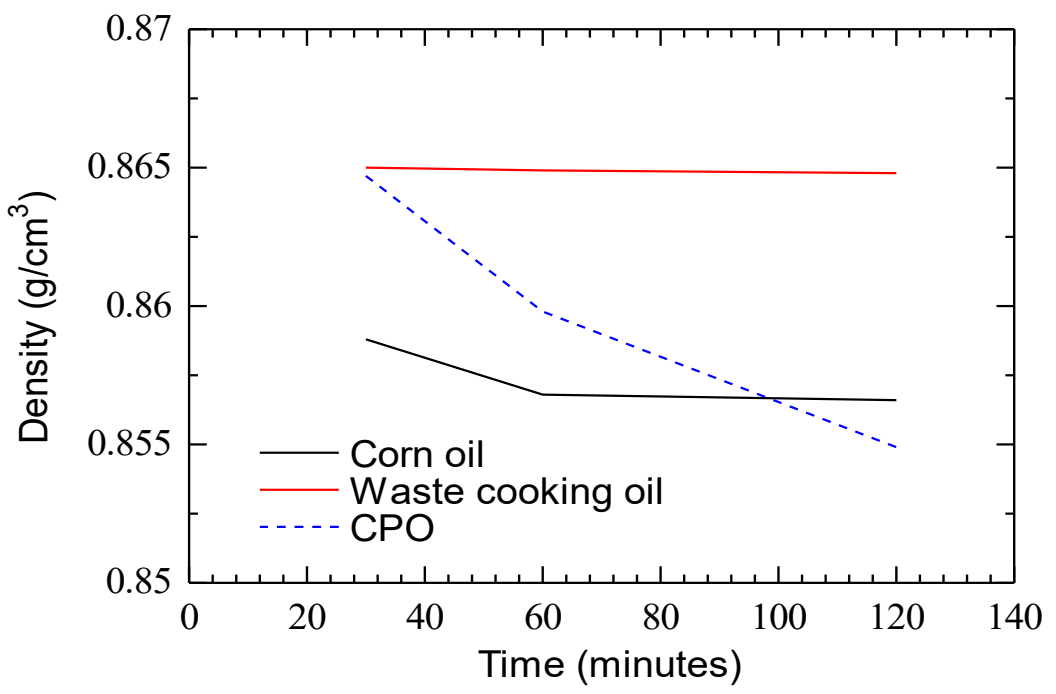

Fig. 5. The comparison of the density of corn oil, waste cooking oil and $\mathrm{CPO}$

At $30 \mathrm{~min}$, the density of the biodiesel sample from corn oil is higher but then decreases when the time is increased. Meanwhile, the density of the biodiesel samples from waste cooking oil is slightly higher than biodiesel from CPO, which is $0.0003 \mathrm{~g} / \mathrm{cm}^{3}$. At 60 minutes, the sample does not show too much difference. But, at 30 minutes, the density of the biodiesel sample from CPO is 0.8647 $\mathrm{g} / \mathrm{cm}^{3}$, but at 120 minutes, the density of the biodiesel sample decreases to $0.8549 \mathrm{~g} / \mathrm{cm}^{3}$. Compared to biodiesel samples from corn oil and waste cooking oil simultaneously, the density of CPO is lower 
than the others, which are $0.8549 \mathrm{~g} / \mathrm{cm}^{3}$. On the other hand, the densities of biodiesels will vary with the fatty acid composition and purity, as noted by Tat and Jon [28]. Therefore, it was found that the density of the biodiesel decreases with the increase in time.

\subsection{The Comparison of The Flash Point of Corn Oil, Waste Cooking Oil and CPO}

The flash point of a fuel is defined as the temperature at which the fuel becomes a mixture that will ignite when exposed to a spark or flame. But, in this study the temparature, methanol content and catalyst are constant with the value of $60{ }^{\circ} \mathrm{C}$ to $70{ }^{\circ} \mathrm{C}, 21.696$ gram and $1 \%$ of catalyst, respectively. The time is the only variable. As can be seen in Figure 6, when the time was 30 minutes, the three biodiesel samples have a low flash point values which are $169^{\circ} \mathrm{C}, 168^{\circ} \mathrm{C}$ and 172 ${ }^{\circ} \mathrm{C}$ for corn oil, waste cooking oil and $\mathrm{CPO}$ respectively. The increase in the flash point was occurred at 60 minutes, in which samples of biodiesel from CPO has a flash point higher than the value of the other two samples of biodiesel, which is $175^{\circ} \mathrm{C}$. While, at the time of 120 minutes, the flash point value for all biodiesel samples has increased. In this study, the flash point value from biodiesel waste cooking oil samples has similar increase with biodiesel sample from CPO which is $176{ }^{\circ} \mathrm{C}$. Whereas, the flash point for biodiesel sample from corn oil increased up to $174{ }^{\circ} \mathrm{C}$ only. However, it was found that the value of flash point that is obtained in this study still within the standard.

Graboski and McCormick [29] noted that the fuel with high flash point is highly coveted, as the risk associated with fuel transportation is greatly minimised. This is attributed to the inability of combustible air fuel vapour mixture to ignite below the flash point. Flash point strictly corresponds to the methanol content. Specifically, flash point is used in safety regulations to define "flammable" and "combustible" materials [30]. Flash point is the number indicating flammability when given a spark.

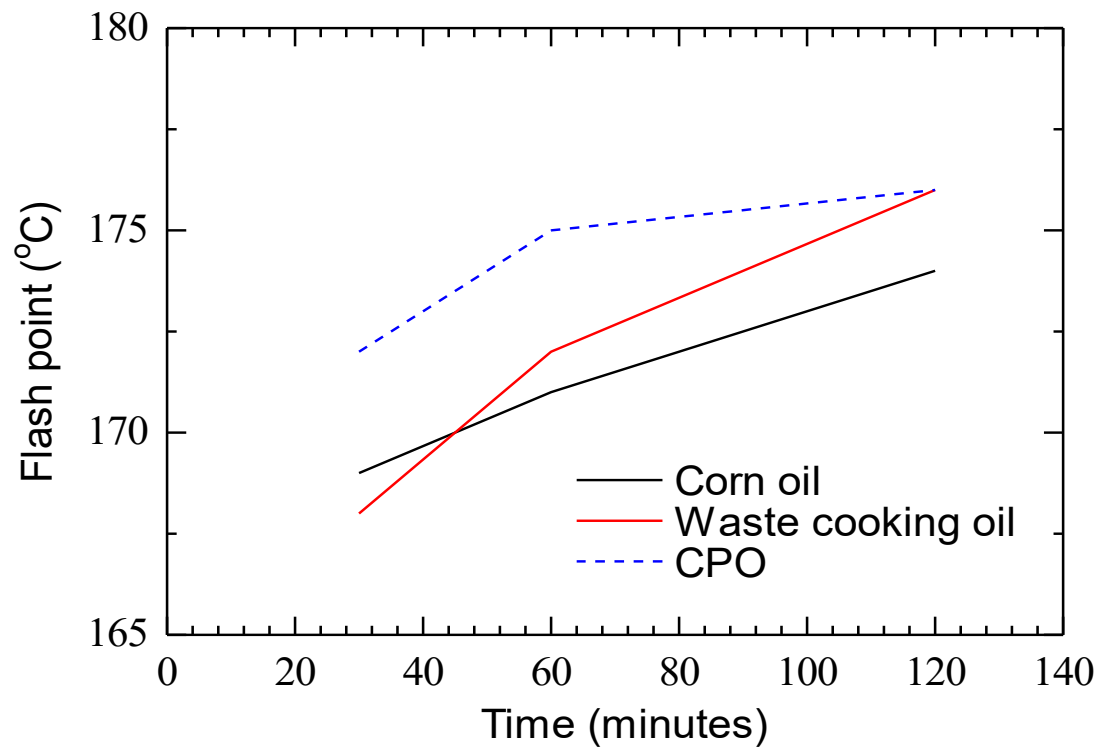

Fig. 6. The comparison of the flash point of corn oil, waste cooking oil and $C$ 


\subsection{The Comparison of The Acid Value of Corn Oil, Waste Cooking Oil and CPO}

At the beginning of the study, there were differences in acid content of raw materials. Compared with waste cooking oil and CPO, corn oil has an acid value lower than the others which are 0.5565 $\mathrm{mg} \mathrm{KOH} / \mathrm{g}$. While the acid value of waste cooking oil and $\mathrm{CPO}$ are respectively $0.5599 \mathrm{mg} \mathrm{KOH} / \mathrm{g}$ and $6.786 \mathrm{mg} \mathrm{KOH} / \mathrm{g}$. Reactions were carried out at $60{ }^{\circ} \mathrm{C}$ to $70{ }^{\circ} \mathrm{C}$ for 30 minutes, 60 minutes and 120 minutes using a feedstock to methanol molar ratio of 1:6. The catalyst concentration was $1 \%(\mathrm{v} / \mathrm{v})$. The drop in acid content was used as a measure to calculate the percentage of conversion of feedstock to biodiesel. The difference is probably due to the type of oil. The acid value indicates the content of free fatty acid in biodiesel.

Corn oil has a low percentage of saturated fats and trans fats. Table 2 shows the difference in acid content between the 9 samples of biodiesel. From the results of this study, acid value from was cooking oil was found to decline when the time taken for the transesterification process is longer. Leung et al., [31] has found that the acid content was obtained $2.5 \mathrm{mg} \mathrm{KOH} / \mathrm{g}$. But a study from Phan and Phan [27] found that the acid content in waste cooking oil was $0.43 \mathrm{mg} \mathrm{KOH} / \mathrm{g}$. These two studies show that the acid content is lower than this findings. The difference is probably due to the production of cooking oil itself in which that it is strongly dependant on the yield of methyl ester. This can also be caused by brand, the location to produce oil production, and the manufacturing process. Biodiesel from CPO samples have the highest acid content compared to other samples maybe due to the presence of oxygen. That is why, to reduce the acid content, it is necessary to do esterification process first.

To test an engine performance, biodiesel which has the lowest acid content is to be preferred. In this study, the samples from corn oil at the time of 120 minutes are better than the other 8 samples.

\section{Conclusions}

The physical properties of biodiesel samples in terms of viscosity, density, flash point and acid values were investigated at different biolipids and different mixing time. The following conclusions are obtained.

i. Using clean raw materials (waste cooking oil and corn oil) leads to biodiesel that is easier to produce. The esterification process has been performed on the CPO samples due to the higher acid content, which is $10.92 \mathrm{mg} \mathrm{KOH} / \mathrm{g}$.

ii. In terms of viscosity, the biodiesel samples of corn oil and CPO at time 120 minutes and $40^{\circ} \mathrm{C}$ is better than the others, which are $3.3 \mathrm{~mm}^{2} / \mathrm{s}$. The density of biodiesel from CPO samples at 120 minutes is the lowest, which is $0.8549 \mathrm{~g} / \mathrm{cm}^{3}$ compared to the other sample.

iii. In terms of acid value, biodiesel from corn oil is better compared to other samples. However, $\mathrm{CPO}$ at 30 minutes had a larger acid content value of $2.088 \mathrm{KOH} / \mathrm{g}$, and at 120 minutes, it decreased to $1.543 \mathrm{KOH} / \mathrm{g}$. The acid values for waste cooking oil did not differ much, 0.550 $\mathrm{KOH} / \mathrm{g}, 0.544 \mathrm{KOH} / \mathrm{g}$ and $0.537 \mathrm{KOH} / \mathrm{g}$ at 30,60 and 120 minutes.

iv. In terms of flashpoint, biodiesel samples from waste cooking oil and CPO at time 120 minutes are better, $176{ }^{\circ} \mathrm{C}$ respectively.

v. The comparison of 9 samples shows that CPO is the better biodiesel than the other due to the physical properties of kinematic viscosity, density and flashpoint. 


\section{Acknowledgement}

The authors would like to express their appreciation to Universiti Teknologi Malaysia and Takasago Thermal Engineering Co. Ltd., Japan, for providing financial support for this work through (Vote No: 4B631) and also Universiti Tun Hussein Onn Malaysia for their support.

\section{References}

[1] Yusof, Siti Nurul Akmal, Abreeza Manap, Nurfanizan Mohd Afandi, Musdalilah Salim, and Halina Misran. "Mechanical and wear properties of aluminum coating prepared by cold spraying." In AIP conference proceedings, vol. 1669, no. 1, p. 020044. AIP Publishing LLC, 2015. https://doi.org/10.1063/1.4919182

[2] Davies, John, Michael Grant, John Venezia, and Joseph Aamidor. "Greenhouse gas emissions of the US transportation sector: Trends, uncertainties, and methodological improvements." Transportation research record 2017, no. 1 (2007): 41-46. https://doi.org/10.3141/2017-06

[3] Yusof, Siti Nurul Akmal, Yutaka Asako, Mohammad Faghri, Lit Ken Tan, and Nor Azwadi bin Che Sidik. "Numerical analysis for irreversible processes in a piston-cylinder system." International Journal of Heat and Mass Transfer 124 (2018): 1097-1106. https://doi.org/10.1016/i.ijheatmasstransfer.2018.04.008

[4] Yusof, Siti Nurul Akmal, Yutaka Asako, Mohammad Faghri, Lit Ken Tan, Nor Azwadi bin Che Sidik, and Wan Mohd Arif bin Aziz Japar. "Numerical analysis of irreversible processes in a piston-cylinder system using LB1S turbulence model." International Journal of Heat and Mass Transfer $136 \quad$ (2019): $730-739$. https://doi.org/10.1016/j.ijheatmasstransfer.2019.03.007

[5] Yusof, Siti Nurul Akmal, Yutaka Asako, Tan Lit Ken, and Nor Azwadi Che Sidik. "Piston surface pressure of pistoncylinder system with finite piston speed." Journal of Advanced Research in Fluid Mechanics and Thermal Sciences 44, no. 1 (2018): 55-65.

[6] Yusof, Siti Nurul Akmal, Nor Azwadi Che Sidik, Yutaka Asako, Wan Mohd Arif Aziz Japar, Saiful Bahri Mohamed, and Nura Mu'az Muhammad. "A comprehensive review of the influences of nanoparticles as a fuel additive in an internal combustion engine (ICE)." Nanotechnology Reviews 9, no. 1 (2020): 1326-1349. https://doi.org/10.1515/ntrev-2020-0104

[7] Mirus, Muhammad Farhan, Nurul Fitriah Nasir, Ishkrizat Taib, Azian Hariri, Normayati Nordin, and Norasikin Mat Isa. "A short review on biodiesel production and costing." Journal of Advanced Research in Fluid Mechanics and Thermal Sciences 53, no. 2 (2019): 146-156.

[8] Veljković, Vlada B., Milan O. Biberdžić, Ivana B. Banković-llić, Ivica G. Djalović, Marija B. Tasić, Zvonko B. Nježić, and Olivera S. Stamenković. "Biodiesel production from corn oil: A review." Renewable and Sustainable Energy Reviews 91 (2018): 531-548. https://doi.org/10.1016/i.rser.2018.04.024

[9] Caliskan, Hakan, and Kazutoshi Mori. "Thermodynamic, environmental and economic effects of diesel and biodiesel fuels on exhaust emissions and nano-particles of a diesel engine." Transportation Research Part D: Transport and Environment 56 (2017): 203-221. https://doi.org/10.1016/i.trd.2017.08.009

[10] Singh, Digambar, Dilip Sharma, S. L. Soni, Sumit Sharma, Pushpendra Kumar Sharma, and Amit Jhalani. "A review on feedstocks, production processes, and yield for different generations of biodiesel." Fuel 262 (2020): 116553. https://doi.org/10.1016/i.fuel.2019.116553

[11] Sharma, Pushpendra Kumar, Dilip Sharma, Shyam Lal Soni, Amit Jhalani, Digambar Singh, and Sumit Sharma. "Energy, exergy, and emission analysis of a hydroxyl fueled compression ignition engine under dual fuel mode." Fuel 265 (2020): 116923. https://doi.org/10.1016/i.fuel.2019.116923

[12] Mamat, R., M. S. M. Sani, K. Sudhakar, Asep Kadarohman, and R. E. Sardjono. "An overview of Higher alcohol and biodiesel as alternative fuels in engines." Energy Reports 5 (2019): $467-479$. https://doi.org/10.1016/i.egyr.2019.04.009

[13] Çelebi, Yahya, and Hüseyin Aydın. "An overview on the light alcohol fuels in diesel engines." Fuel 236 (2019): $890-$ 911. https://doi.org/10.1016/i.fuel.2018.08.138

[14] Win, Shwe Sin, and Thomas A. Trabold. "Sustainable Waste-to-Energy Technologies: Transesterification." In Sustainable Food Waste-To-energy Systems, pp. 89-109. Academic Press, 2018. https://doi.org/10.1016/B9780-12-811157-4.00006-1

[15] Suwannakarn, Kaewta. "Biodiesel production from high free fatty acid content feedstocks." (2008).

[16] Zhang, Yen, M. A. Dube, D. D. L. McLean, and M. Kates. "Biodiesel production from waste cooking oil: 1. Process design and technological assessment." Bioresource technology 89, no. $1 \quad$ (2003): 1-16. https://doi.org/10.1016/S0960-8524(03)00040-3

[17] Sharma, Y. C., B. Singh, and S. N. Upadhyay. "Advancements in development and characterization of biodiesel: a review." Fuel 87, no. 12 (2008): 2355-2373. https://doi.org/10.1016/j.fuel.2008.01.014 
[18] Ahmad, Zunairah, Rosnani Hasham, NF Aman Nor, and M. R. Sarmidi. "Physico-chemical and antioxidant analysis of virgin coconut oil using West African tall variety." Journal of Advanced Research in Materials Science 13, no. 1 (2015): 1-10.

[19] Che Hamzah, Nurul Husna, Nozieana Khairuddin, Bazlul Mobin Siddique, and Mohd Ali Hassan. "Potential of Jatropha curcas L. as Biodiesel Feedstock in Malaysia: A Concise Review." Processes 8, no. 7 (2020): 786. https://doi.org/10.3390/pr8070786

[20] Zahan, Khairul Azly, and Manabu Kano. "Biodiesel production from palm oil, its by-products, and mill effluent: a review." Energies 11, no. 8 (2018): 2132. https://doi.org/10.3390/en11082132

[21] Kumaran, P., Nur Mazlini, Ibrahim Hussein, M. Nazrain, and M. Khairul. "Technical feasibility studies for Langkawi WCO (waste cooking oil) derived-biodiesel." Energy 36, no. $3 \quad$ (2011): 1386-1393. https://doi.org/10.1016/i.energy.2011.02.002

[22] Asli, Hallizza, Esmaeil Ahmadinia, Majid Zargar, and Mohamed Rehan Karim. "Investigation on physical properties of waste cooking oil-Rejuvenated bitumen binder." Construction and Building Materials 37 (2012): 398-405. https://doi.org/10.1016/i.conbuildmat.2012.07.042

[23] Meher, L. ĈT, D. Vidya Sagar, and S. N. Naik. "Technical aspects of biodiesel production by transesterification $-a$ review." Renewable and sustainable energy reviews 10, no. $3 \quad$ (2006): $248-268$. https://doi.org/10.1016/j.rser.2004.09.002

[24] Ma, Fangrui, and Milford A. Hanna. "Biodiesel production: a review." Bioresource technology 70, no. 1 (1999): $1-$ 15. https://doi.org/10.1016/S0960-8524(99)00025-5

[25] Official Methods and Recommended Practices of the American Oil Chemists' Society, 4th edn., edited by D. Firestone, American Oil Chemists' Society, Champaign, 1989, Ca 5a-40.

[26] Belozertseva, Nataljya Evgenjevna, I. A. Bogdanov, Aryuna Togmitovna Balzhanova, and Mariya Vladimirovna Kirgina. "The choice of feedstock for the biodiesel production with optimal physicochemical and low-temperature properties." In IOP Conference Series: Materials Science and Engineering, vol. 1019, no. 1, p. 012062. IOP Publishing, 2021. https://doi.org/10.1088/1757-899X/1019/1/012062

[27] Phan, Anh N., and Tan M. Phan. "Biodiesel production from waste cooking oils." Fuel 87, no. 17-18 (2008): 34903496. https://doi.org/10.1016/i.fuel.2008.07.008

[28] Tat, Mustafa E., and Jon H. Van Gerpen. "The specific gravity of biodiesel and its blends with diesel fuel." Journal of the American Oil Chemists' Society 77, no. 2 (2000): 115-119. https://doi.org/10.1007/s11746-000-0019-3

[29] Graboski, Michael S., and Robert L. McCormick. "Combustion of fat and vegetable oil derived fuels in diesel engines." Progress in energy and combustion science 24, no. 2 (1998): 125-164. https://doi.org/10.1016/S03601285(97)00034-8

[30] Kinast, John A. Production of biodiesels from multiple feedstocks and properties of biodiesels and biodiesel/diesel blends. National Renewable Energy Laboratory, 2003. https://doi.org/10.2172/15003582

[31] Leung, Dennis YC, Xuan Wu, and M. K. H. Leung. "A review on biodiesel production using catalyzed transesterification." Applied energy 87, no. 4 (2010): 1083-1095. https://doi.org/10.1016/i.apenergy.2009.10.006 